Austral Comunicación

Volumen 10, número 1 (junio de 2021): e1-e3

ISSN (I) 2313-9129. ISSN (E) 2313-9137

\title{
Damián Loreti, Diego de Charras, Luis Lozano y Mariela Baladron Futuro por pasado: regresión de derechos en las políticas de comunicación de Mauricio Macri
}

Buenos Aires. Universidad de Buenos Aires, 2020, 236 pp.

ISBN 978 950-29-1880-8.

El surgimiento de gobiernos populares en los albores del siglo XXI en Latinoamérica suscitó grandes debates en torno al acceso equitativo y plural de los diferentes actores a los medios de comunicación. Tanto las nuevas leyes regulatorias, como las políticas públicas de comunicación establecieron un quiebre con el paradigma neoliberal reinante en la década de los noventa. Si bien con diferentes matices e intensidades, y luego de mucho tiempo, cada Estado ponía en tela de juicio la fuerte concentración en la propiedad existente en el sector, como así también el trato meramente mercantil que recibía la comunicación hasta entonces.

En esta dirección, la Argentina, bajo las dos presidencias de Cristina Fernández de Kirchner, no fue indiferente al clima de la época. Durante 2009, luego de un enérgico debate social de alcance nacional, fue sancionada la Ley 26.522 de Servicios de Comunicación Audiovisual (LSCA). La nueva normativa daba un giro rotundo de concepción y partía de considerar a la comunicación como un derecho humano básico a garantizar por parte del Estado. Un lustro después y con la misma perspectiva, el Congreso Nacional sancionó la Ley 27.078, conocida como "Argentina Digital". Con esta nueva legislación se buscaba garantizar el acceso a las nuevas Tecnologías de la Información y la Comunicación (TIC) al total de la población.

Sin embargo, y como era esperable, esta nueva concepción en las políticas comunicativas no fue recibida de forma armoniosa por aquellos grupos concentrados de la comunicación que veían peligrar sus estructuras de negocios y poder. En relación con esto, Futuro por Pasado alude al lapso histórico kirchnerista como una etapa signada por una tensión fortísima entre el gobierno y el Grupo Clarín, principal conglomerado mediático de la Argentina. Uno de los puntos más críticos de los enfrentamientos quedó plasmado con el recurso de amparo presentado por este multimedio ante la Corte Suprema de la Nación. Esta acción suspendió hasta 2013 cuatro artículos de la LSCA $(41,45,48$, 161), de los que se destacan aquellos que hacían mención al límite y la concentración de licencias, como al tiempo de adecuación que debían tener los distintos multimedios a la nueva normativa.

Del mismo modo, en medio de tal crispación transcurren las elecciones presidenciales 2015. Los resultados dan por ganadora a la Alianza Cambiemos liderada por la fórmula Macri-Michetti. En relación con ello, desde la obra se señala que la apoyatura de los medios concentrados de comunicación a la fórmula de la alianza durante la campaña electoral hacía esperable un vuelco rotundo en las políticas públicas de comunicación, aunque nadie podía pronosticar cómo ni cuándo sucedería.

Para abordar el análisis del periodo, cuatro personas claves en la cuestión editan Futuro por pasado: Damián Loreti, doctor en Ciencias de la Información, Luis Lozano, exdirector del área de Comunicación del Centro de Estudios Legales y Sociales, 
ambos redactores de la LSCA. Diego de Charras, coordinador del área de Legislación y Regulación de la Red de carreras de Comunicación Social y Periodismo, y Mariela Baladron, investigadora de la industria cultural, también con amplia trayectoria en la temática. Futuro por Pasado se convierte así en un aporte fundamental en los estudios que rigen la jurisprudencia de la comunicación en la Argentina, que sigue la misma línea de títulos anteriores como Las Políticas de Comunicación en el Siglo XXI (Charras, Mastrini y Bizberge, 2013) o El derecho a Comunicar" (Loreti y Lozano, 2014).

Con una postura enunciativa global, desde la obra no se vacila en sostener que el nuevo gobierno de la Alianza Cambiemos ha sido el primer partido político elegido democráticamente con un plan de corte neoliberal explícito. De este modo, a lo largo de la obra se compondrán las huellas impregnadas de esta forma de entender la política y la economía en las diferentes decisiones relacionadas con la regulación en materia de comunicación en la Argentina.

En cuanto a su título, se lo puede pensar como una doble referencia muy sutil. Primero, como remisión inmediata al fallido de la electa gobernadora de la provincia de Buenos Aires por Cambiemos, María Eugenia Vidal, quien en el día de su triunfo electoral soltó las palabras "Cambiamos futuro por pasado”, mirando a las cámaras de televisión. Sin embargo, en un segundo aspecto también, como un postulado que, al calor del análisis de las distintas resoluciones en las políticas de comunicación del nuevo gobierno, cobra sentido relacional con un pasado regulatorio previo a la LSCA marcado por las políticas mercantilistas de la comunicación.
A su vez, de forma coloquial y con la utilización de lenguaje inclusivo en diferentes formatos, en los primeros dos capítulos: "Cuatro años de precarización institucional, concentración y regresividad" y "Cambios 2016: el Decreto 267, ENACOM y después”, los autores presentan los primeros cambios y decisiones tomadas por el nuevo gobierno y cómo estas implicaron un viraje rotundo en las políticas que se venían tomando hasta el momento.

En cuanto al capítulo tres, "La Comisión Redactora de la ley de comunicaciones convergentes: principios difusos y ficciones de participación", se describe la creación, la composición y el funcionamiento de la comisión que se encargaría de redactar una nueva Ley de Comunicaciones. El proyecto, finalmente, no vería la luz durante todo el gobierno de la Alianza Cambiemos.

Asimismo, el capítulo seis muestra el cambio de perspectiva en relación con la política de soberanía espacial en el país. Por su parte, los capítulos siete, ocho y nueve también puede ser pensado como un bloque de sentido propio. En ellos, se hace foco en los cambios en la gestión estatal de Radio y Televisión Argentina (RTA SE), el ahogo a través de la quita de la pauta oficial a medios con una línea editorial favorable al arco opositor y el tratamiento comparativo de proyectos de ley que intentaron regular la pauta oficial. En cuanto al capítulo diez, se muestran los pormenores históricos que llevaron en 2016 a la aprobación de Ley de Acceso a la Información Pública. Finalmente, el capítulo once analiza de forma muy detallada el comienzo y la posterior eliminación del programa Fútbol Para todos, que significó el retorno lucrativo a la retransmisión de este deporte 
Austral Cmunicación

Volumen 10, número 1 (junio de 2021): e1-e3

ISSN (I) 2313-9129. ISSN (E) 2313-9137

por televisión y una pérdida al derecho social de este consumo cultural.

A modo de conclusión, Futuro por pasa$d o$, gracias a su lenguaje coloquial, puede ser comprendido por un lector sin conocimientos previos en la materia, sin perder por ello profundidad ni exactitud en sus explicaciones. Ofrece una radiografía de los medios de comunicación durante los dos primeros años del macrismo. Permite entender el cambio en la toma de posición del Estado en el mapa de los medios, en donde se pasó de una concepción de la comunicación como derecho humano básico, a una mirada centrada en la comunicación como un negocio.

\section{Referencias}

Loreti, M. y Lozano, L. (2014). El derecho a comunicar. Cúspide.

Mastrini, G., Bizberge, A., De Charras, D. (Eds.). (2013). Las políticas de comunicación en el siglo XXI. La Crujía.

Daniel Cuevas

Universidad Nacional de Moreno dcuevas305@gmail.com ORCID: https://orcid.org/0000-0001-7753-8894

Julieta Cardozo

Universidad Nacional de Moreno defreitasjulieta@gmail.com ORCID: https://orcid.org/0000-0001-9279-3906 